\title{
Paisagens suspensas nas obras de Kishio Suga
}

\author{
Suspended Landscapes in the Kishio Suga's Artwork
}

Paisajes suspendidos en el trabajo de Kishio Suga

Anais Alves Pereira (Universidade de São Paulo, Brasil) *

https://doi.org/10.22409/poiesis.v21i36.41198

\begin{abstract}
RESUMO: O presente artigo trata da obra do artista japonês Kishio Suga, integrante do grupo de arte do pós-guerra Mono-ha, e aborda especialmente seus trabalhos em instalação, tratando da interação destes com a arquitetura. A percepção do artista sobre a "matéria", estabelecida a partir de seu conceito de mono (coisa), é analisada por meio das noções de espaço, paisagem e site-specific, tendo como base os autores Anne Cauquelin, Milton Santos e Miwon Kwon. Os contrastes entre natural e artificial, muito presentes na obra de Kishio Suga, são explanados partindo das análises do antropólogo Bruno Latour acerca da modernidade e as relações entre natureza e cultura.
\end{abstract}

PALAVRAS-CHAVE: natureza; arquitetura; paisagem; Kishio Suga; instalação

\footnotetext{
* Anais Alves Pereira é doutoranda no Programa de Pós-Graduação de Artes Visuais (PPGAV) da Universidade de São Paulo (USP). E-mail: anaiskarenin@gmail.com. Orcid: https://orcid.org/0000-0002-3465-7671
} 
ABSTRACT: This article deals with the work of the Japanese artist Kishio Suga, a member of the post-war art group Mono-ha, especially addressing his works in installation and dealing with his interaction with architecture. The artist's perception of "matter", established from his concept of mono (thing), is analyzed through the notions of space, landscape and site-specific based on the authors Anne Cauquelin, Milton Santos and Miwon Kwon. The contrasts between natural and artificial, very present in the work of Kishio Suga, are explained based on the anthropologist Bruno Latour's analysis of modernity and the relationships between nature and culture.

KEYWORDS: nature; architecture; landscape; Kishio Suga; installation

RESUMEN: Este artículo trata sobre el trabajo del artista japonés Kishio Suga, miembro del grupo de arte de posguerra Mono-ha, en especial el abordaje de sus obras en instalación y tratando de su interacción con la arquitectura. La percepción del artista de la "materia", establecida a partir de su concepto de mono (cosa), se analiza a través de las nociones de espacio, paisaje y site-specific basadas en los autores Anne Cauquelin, Milton Santos y Miwon Kwon. Los contrastes entre lo natural y lo artificial, muy presentes en el trabajo de Kishio Suga, se explican en base al análisis de la modernidad del antropólogo Bruno Latour y las relaciones entre la naturaleza y la cultura.

PALABRAS CLAVE: naturaleza; arquitectura; paisaje; Kishio Suga; instalación

Citação recomendada:

PEREIRA, Anais Alves. Paisagens suspensas nas obras de Kishio Suga. Revista Poiésis, Niterói, v. 21, n. 36, p. 245-262, jul./dez. 2020.

[https://doi.org/10.22409/poiesis.v21i36.41198]

(cc) BY-NC-ND Este documento é distribuído nos termos da licença Creative Commons Atribuição-NãoComercial 4.0 Internacional (CC-BY-NC) (c) 2020 Anais Alves Pereira

Anais Alves Pereira, Paisagens suspensas nas obras de Kishio Suga. 


\section{Paisagens suspensas nas obras de Kishio Suga}

A proposta de instalação como objeto, que cria uma área especial de coexistência ao seu redor, é oferecida pelo artista japonês Kishio Suga como meio de constituir um "mundo" através dos materiais e ativar relações entre o espaço, as coisas e as pessoas. $O$ presente texto trata especialmente da obra desse artista e da maneira como ela se relaciona com a materialidade e a arquitetura, constituindo paisagens em suspensão. Para Suga, a arte deveria se tornar um meio para mudar os espaços físicos e linguísticos, os conceitos fixos, as estruturas antropológicas, a religião e a espiritualidade, ao invés de abordar as ações humanas e o mundo das ideias.

Kishio Suga explorou "a interseção entre o eixo vertical da arquitetura feita pelo homem e o plano horizontal do mundo natural". (SUGA, 2017, p. 2) Em um caderno da década de 1970, ele escreveu sobre querer tornar "paredes e pisos aparentes", ressaltando a construção espacial feita pelo ser humano em oposição à natureza. Assim como as coisas não são meros materiais no trabalho de Suga, também o espaço não é neutro dentro da constituição das instalações. Há sempre uma relação prévia que irá determinar a montagem, possibilitando que o público se torne consciente do espaço junto das coisas que lhe são inerentes e que ali foram incutidas, observando os pontos de conexão presentes e os novos limites que são estabelecidos.

Parte do Mono-ha, Kishio Suga foi o único artista que permaneceu investigando a estética do grupo durante toda sua trajetória criativa $^{1}$. Em japonês, Moho-ha significa "Escola das Coisas"; o grupo surgiu no pe- 
ríodo do pós-guerra no Japão. Os artistas propunham a criação de objetos de arte com materiais simples, enfatizando o relacionamento da obra com o espaço circundante e com locais ao ar livre. Seu objetivo era simplesmente reunir "coisas" na medida do possível, em um estado inalterado -, permitindo que os materiais justapostos falassem por si mesmos, desafiando as percepções preexistentes e relacionando-se com eles em outro nível.

A partir de 1970, Kishio Suga começou a realizar o que intitulou de "trabalhos de campo". Essas intervenções, realizadas diretamente em espaços ao ar livre, utilizavam materiais simples em composições integradas à paisagem, que acabavam por criar relações novas de percepção do espaço, ativadas pela interação dos elementos. Na obra Elemental Realm (1974), o artista lida mais diretamente com a proposição da land art; já em Appearing Space (1982, Fig. 1) e Floating Units of Per-ception (1973), as obras indicam um caminho na direção de uma construção espacial. É como se o artista compusesse pequenos esboços arquitetônicos, em vista de uma habitação para as coisas e não para as pessoas. Realizadas diretamente na paisagem e como composições efêmeras, essas obras sobrevivem como registros fotográficos e marcam um percurso importante no desenvolvimento de obras posteriores.

Já as instalações de Kishio Suga são obras responsivas, que estabelecem encontros visuais e físicos entre coisas comuns e completamente distintas, principalmente objetos naturais e industriais. Sua intenção é a de não objetificar as coisas ("mono"), "not treat 'things' as mere materials [...] just present something that exists in the world", percebendo-as como são, sem conceitualização ou epistemologia. "Everything that surround us has its own kind of existence, and collectively they form a single worldview". Suga afirma estar interessado no fato de que as coisas mudam de momento a momento, a depender da situação em que são colocadas. Neste sentido, o artista reflete sobre a relação entre as coisas, a arquitetura e a presença humana: "the introduction of human presence and one's own thought also become the object of perception"2.

Em seu envolvimento com as matérias, o artista adentra em um embate com os pro- 


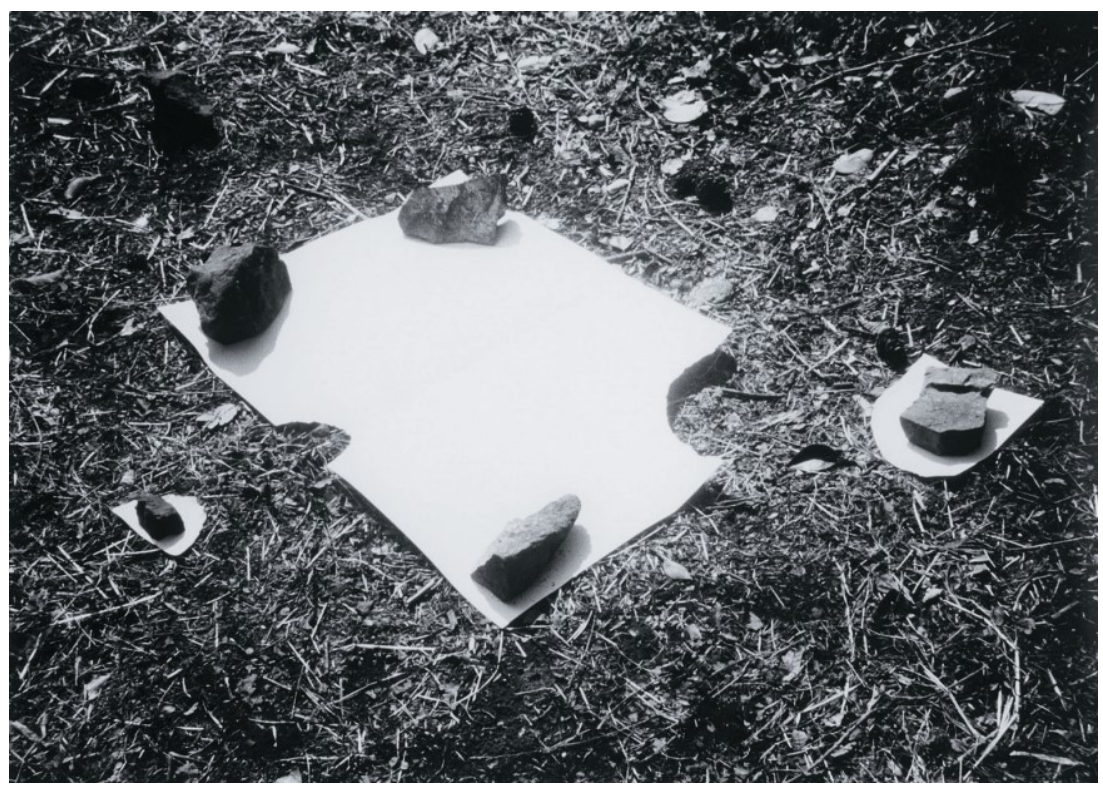

Fig. 1 - Kishio Suga, Appearing Space, 1982.

c-print, $20 \times 28,3 \mathrm{~cm}$

(Fonte: https://www.kishiosuga.com/fieldwork-appearing-space-1982. Acessado em

28/3/2019) 
cessos de racionalização, definição e interpretação fechada do que as coisas são. Nesse âmbito, percorre questões que se conectam a instâncias amplas do processo criativo, tratando da própria noção do que é o fazer artístico, tentando compreender o artista como um intermediário. Deixar um tronco em pé ou na diagonal não significa criar o tronco, mas apenas evidenciar sua capacidade de estar em pé ou em diagonal, evidenciar a capacidade subjetiva das "coisas” (mono), partindo de uma relação íntima com as paisagens internas que habitam as materialidades e com a relação própria que elas estabelecem com o espaço ao redor. Há na proposição do artista um movimento que parece estar em busca de extrair essas paisagens internas e projetá-las no espaço arquitetônico de forma subjetiva. "When a 'thing' no longer becomes a 'thing,' they possess a new site of encounter". (SUGA, 1970, p. 5)

De acordo com o geógrafo Milton Santos, o espaço se difere da paisagem justamente por ter suas definições alteradas em função da significação social. A paisagem se dá como conjunto de formas concretas, é transtemporal e visível. "Já o espaço resulta da intrusão da sociedade nessas formas-objetos. Por isso, esses objetos não mudam de lugar, mas mudam de função, isto é, de significação, de valor sistêmico" (SANTOS, 2006, p. 67) e se dá como um conjunto de conceitos em constante transformação. O espaço estaria aí em função "do valor que a sociedade, em um dado momento, atribui a cada pedaço de matéria, isto é, cada fração da paisagem". (SANTOS, 2006, p. 67) Esse sistema de significações tanto limita experiências amplas como pode servir para abranger outros sentidos espaciais e constituir infinitas possibilidades alteradas pela atribuição de sentidos.

Partindo desses conceitos, a arquitetura, enquanto espaço (construído), estaria sujeita a condições de significação social, enquanto a paisagem se estende pelas formas e para além da forma (transtemporalidade). As instalações de Kishio Suga se localizam de maneira transversal a essas duas definições. Por um lado, lidando diretamente com o significado dos materiais, e suas possíveis releituras a partir da arte - que está sujeita à interpretação social. Por outro lado, reivindicando a condição do elemento natural que transpõe a "ideia" impregnada sobre ele, reme- 
tendo mais diretamente à paisagem. Se essa, por sua vez, está ligada às reflexões existenciais, a arquitetura se envolve mais diretamente com as resoluções ambientais e estruturais humanas.

\section{A obra Left-Behind Situation (Shachi} Jokyo) (Fig. 2) evidencia com clareza um gesto constante no trabalho de Suga de adaptar sua criação à arquitetura. A instalação consiste em um único fio industrial, que é esticado em dois níveis, com uma camada acima da outra, preso em diversos pontos da parede. Nos pontos de intersecção diagonal e horizontal do fio são colocados pedras e pedaços de madeira em equilíbrio.

Em algumas montagens dessa obra, o fio confunde-se com o espaço e as madeiras e pedras parecem flutuar. Em outras condições, as tramas do fio se sobressaem, dando uma impressão de área de contenção. Em ambos os casos, a instalação parece suspender o tempo, colocando o espectador em um estado de leveza ou densidade contemplativa, em que o corpo e o tempo humanos são instantaneamente absorvidos e anulados para dar lugar ao caráter estático da obra.
Os elementos naturais da instalação são apenas colocados e elevados por um fio industrial à altura da visão humana, como se ali pudessem expressar a qualidade de sua presença. No entanto, há um excesso de elementos que, embora únicos, são também extremamente semelhantes entre si: em suas cores, texturas, formas e pesos. Por essa similaridade e repetição, tem-se a impressão de um equilíbrio rígido, afirmado pela tensão do fio que não se curva diante do peso dos materiais. A madeira reconstitui a presença de árvore $e$, no entanto, em contato com outras matérias, passa a comunicar outro tipo de visão.

A estabilidade da obra é aflitiva, pois um pequeno balanço em um dos pontos pode desencadear uma queda atrás da outra. Mas a tensão não é gerada somente pela instabilidade como também pelo próprio fio industrial, que responde a essa fragilidade esticando-se ao ponto de tornar quase irrelevante para si a presença da pedra e da madeira ali dispostas. Enquanto há na obra a presença de uma natureza fisicamente elevada, que poderia comunicar sua condição existencial, permanece também uma condição de vulnerabilidade desta diante da rigi- 


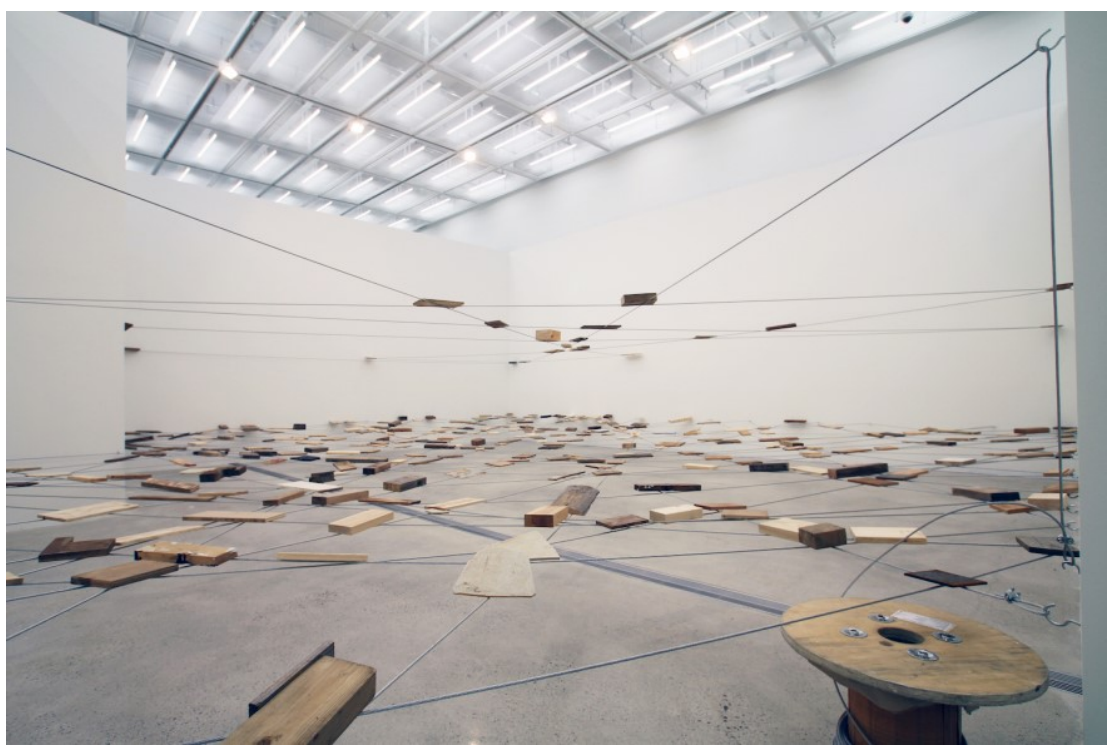

Fig. 2 - Kishio Suga, Left-Behind Situation, 2013.

instalação (madeira, pedra, cabo de aço), dimensões variáveis

(Fonte: https://www.kishiosuga.com/installations-left-behind-situation-1972. Acessado em 28/3/2019) 
dez do pensamento humano e da arquitetura, que se expressam por um fio que não cede. Ou, de outro modo, da rigidez do fio que expressa o pensamento humano, que não admite completamente a presença própria dos materiais e da paisagem que estes constituem no mundo.

A instalação foi montada pela primeira vez em 1972, na galeria Kinokunya, em Tóquio, e remontada em diversas outras oportunidades, sempre adaptando-se de acordo com o espaço expositivo, como uma intervenção temporária. Simon Groom, diretor da Galeria Nacional Escocesa de Arte Moderna de Edimburgo, compara a obra de Suga a uma fotografia que capta um instante fixo e único ${ }^{3}$, por sua condição sutil de adaptação a cada espaço em que é exposta e que, muitas vezes, só é percebida a partir dos registros fotográficos. Essa condição de pausa existe em grande parte de seus trabalhos e é especialmente evidenciada em Left-Behind Situation. A construção de suas instalações assimilam-se à fotografia também nesse sentido, pois muitas de suas obras, embora frágeis, parecem estar completamente acomodadas e congeladas no tempo de seu acontecimento.
A curadora Miwon Kwon entende que os trabalhos de site-specific foram radicalmente deslocados pela materialidade da paisagem natural e se tornaram parte do lugar, reestruturando uma organização conceitual e perceptiva do espaço. No entanto, muitos trabalhos site-specific, com o passar do tempo, foram deixando de se situar em relação ao espaço para se localizar em relação ao discurso do espaço. Esse processo de transformação está imbricado também no desenvolvimento técnico, que gerou dimensões territoriais e, por fim, dimensões informacionais, fazendo com que os lugares se tornassem informação em si mesmos.

\section{Isso significa endereçar-se às diferenças das adjacências e distâncias entre uma coisa, uma pessoa, um lugar, um pensa-mento, um fragmento ao lado do outro, mais do que evocar as equivalências via uma coisa após a outra. (KWON, 2009, p. 184)}

Essas "distâncias entre uma coisa e outra", como afirma Kwon, criam um potencial relacional em que nem tudo é definido. A experiência, por seu lado, permite ultrapassar fronteiras definidas, em que a ação humana não tem o poder de 
controlar tudo. Nesse tipo de criação artística, inclusive, vem a descontrolar.

Nos trabalhos de Kishio Suga, a presença dos elementos naturais parece representar um recurso paisagístico, enquanto os objetos industriais representam o pensamento humano. Ambos estabelecem uma relação com o espaço e as significações inerentes à arquitetura, elementos que Suga jamais ignora na montagem de seus trabalhos. Assim, as obras interagem fisicamente com o espaço, mas ao mesmo tempo acionam a dimensão informacional quanto nos elementos. Ele comunica relações simultâneas entre natureza e cultura, ao remeter ao ambiente natural (por meio da paisagem que habita o interior das rochas e madeiras) e ao ambiente arquitetônico (por meio da relação atenta ao espaço e à presença de matéria industrial típica de processos construtivos). Nesse ponto, as obras revelam também o aspecto não harmônico dessas interações.

Ao discorrer sobre os paradigmas da modernidade, o antropólogo francês Bruno Latour se debruça sobre a problemática do pensamento moderno, que influencia dire-

tamente na forma como lidamos com outras naturezas-culturas, ao separar o que é humano daquilo que não é humano. Latour questiona se seria então necessário criar uma "democracia" que se estendesse ao plano das coisas em si, indagação que remete aos trabalhos de Kishio Suga, na sua busca por apresentar o que não é humano como algo capaz de possuir uma existência própria. Suga diz crer que as pessoas poderiam ser vistas e criticadas pelas coisas, se a estas fosse permitida uma consciência crítica.

Para justificar o modo como chegamos a interações essencialmente distantes entre ser humano e matéria inanimada / natureza, Bruno Latour explica o desenvolvimento do pensamento científico como um centro que separa dois polos: de um lado, o do objeto; do outro, o do sujeito. Neste percurso, a invenção do conceito e do espaço do laboratório reiterou ainda mais esse discurso, uma vez que ali os fatos passaram a ser produzidos por meio de uma recriação de eventos da natureza. Os cientistas se tornam as testemunhas das coisas, em um movimento em que as vozes se confundiram e a racionalidade se sobrepôs às forças naturais. "Quem fala, 
então: a natureza ou os homens?" (LATOUR, 2013, p. 34)

Este paradoxo engendrado pelo desenvolvimento científico, que culminou na crise da razão moderna, é evidenciado pelas obras apresentadas aqui. A busca do artista por eliminar o caráter humano de seus trabalhos acaba por aproximá-lo, em muitos casos, de uma autoridade própria da razão e do pensamento humanos. Mesmo que a matéria seja evidenciada e o gesto seja amenizado, a ausência se dá mais claramente no âmbito físico. Além disso, nestas obras, os objetos e elementos estão colocados constante e inevitavelmente em relação à presença humana, que alteraria a condição das coisas, seguindo o raciocínio da obra de Kishio Suga.

Embora os limites entre materiais industriais e matérias em seu estado próprio sejam bem demarcados, há também em suas obras um aspecto de contaminação que gera uma dança paradoxal entre os limites do humano e do não-humano. Ao reconhecermos claramente a pedra como "pedra", deslocada de seu contexto original, somos capazes de criar uma natureza artificial, que o cérebro humano pode livremente manipular, produzindo uma natureza em que a consciência humana estaria imersa. Deste modo, a atmosfera específica criada pelas instalações não deixa esgotar as questões que propõe. Ao contrário, permite retomar, de algum modo, a relação com a natureza e o espaço ao redor para o centro de nosso foco e de nossa reflexão. Por outro lado, ao colocar essas dimensões em paralelo, o artista parece também evidenciar uma impossibilidade de acordo entre elas, ao menos na condição do mundo contemporâneo.

A obra Gap to the Entrance to the Space (Kainyưsa) (Fig. 3) foi criada em 1979 com placas de zinco sobre o chão, pedras brutas e blocos. No caso dessa instalação, os blocos não são de cimento, mas de pedras com cortes retos, que geram objetos retangulares em dimensões variadas. São pedras que se contrapõem àquelas utilizadas em seu estado bruto. A mesma materialidade é empregada na obra em duas condições distintas de intervenção, constituindo formas orgânicas e geométricas que se interpelam. 


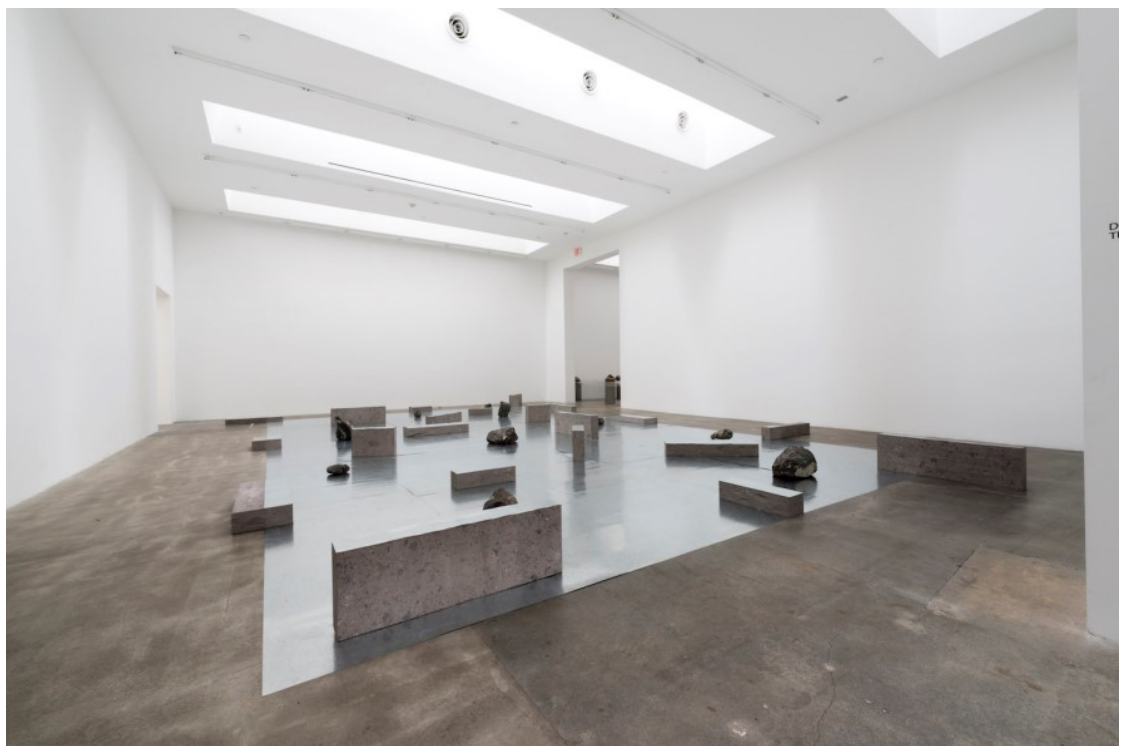

Fig. 3 - Kishio Suga, Gap of the Entrance to the Space, 1979/2012. instalação (placas de zinco, pedras), 30,16 x 681,35 x 752,47 cm

(Fonte: https://www.kishiosuga.com/installations-gap-of-the-entrance-to-the-space-1979. Acessado em 28/3/2019) 
Nas áreas em que se localizam os blocos de pedras cortadas, o artista removeu as seções das placas de zinco abaixo delas e as colocou por sobre as pedras, o que enfatiza ainda mais as diferenças físicas dos materiais. As rugosas reivindicam um estado natural e sem intervenção, com uma presença que salta aos olhos em termos de cor e forma. Já os blocos geométricos, com sua superfície lisa e brilhante, se misturam ao zinco do chão.

Nessa composição, torna-se difícil identificar que há uma mesma qualidade material que liga as pedras entre si. Os diferentes graus de interferência aplicados em ambas coloca uma do lado da natureza e a outra do lado da racionalidade. Em um primeiro olhar, a geométrica é mais rapidamente assimilada à placa de zinco do que à bruta, não apenas por conta de sua superfície recoberta, mas principalmente por suas linhas retas industrialmente elaboradas. Os limites entre natural e industrial se tornam difusos e os aspectos que definem o caráter de uma matéria são tensionados. Por estar mais claramente submetido ao raciocínio humano, o bloco de pedra pode facilmente entrar para 0 grupo de elementos criados pelo ser hu- mano, embora a essência de sua materialidade não tenha sido alterada.

Outro limite difuso da obra se apresenta na relação com o espaço. Se, por um lado, as placas de zinco criam linhas geométricas claras que aparentam demarcar um limite, por outro, os blocos de pedra transbordam à linha dessa superfície e se camuflam propositalmente com o chão. Essa camuflagem é cuidadosamente pensada, uma vez que, em cada montagem que fez desse trabalho, Suga escolheu pedras com cores que se assemelhavam ao chão do espaço expositivo para que se misturassem visualmente com o local. Na área do bloco que escapa à superfície de zinco, a face da pedra aparece pura, sem sobreposição da placa brilhante, que é cortada formando uma linha exatamente paralela com o limite da placa abaixo da pedra. Esse corte gera a sensação de que o bloco interrompe a linha demarcada da placa de zinco e essa se desvia de seu bloqueio, contornando a pedra por cima.

Justamente nesse ponto, parece se localizar a lacuna de entrada para o espaço, indicada no título da obra. Nessa falha intencional, não apenas é possível ver a 
semelhança entre a rocha e o chão do espaço, ou a pedra como pedra, mas também se evidencia uma condição de adaptação. O material é adaptado de acordo com a superfície sobre a qual se encontra, como se essa possibilidade de alteração fosse a lacuna que permite a uma única coisa pertencer a contextos variados.

Entretanto, essa condição de adaptação não ocorre com a pedra bruta, como se sua presença não se adaptasse em nenhum momento ao espaço nem à instalação. Como se estivesse constantemente fora de seu lugar, fora de lógica, de razão, constituindo então uma condição outra de existência. Abre-se um novo espaço de percepção, de imaginação de uma circunstância natural contida na pedra. Nesse contraste, residiria a ausência da natureza como a conhecemos e também sua presença. Portanto, o existir da pedra bruta configura-se também como lacuna, por seu desencaixe em relação ao entorno. Essa lacuna poderia ser lida como uma experiência $M a$, que possibilitaria a entrada para um outro espaço que se localiza além de sua presença física.
Para Anne Cauquelin, a natureza e a paisagem podem ser "um só termo, um só conceito - tocar a paisagem, modelá-la ou destruí-la, é tocar a própria natureza". (CAUQUELIN, 2007, p. 39) Embora essas relações entre natureza e paisagem não sejam tão óbvias, engendradas em relações confusas e ambíguas, é justamente essa condição dúbia que nos possibilita apreender e constituir inúmeras relações com o mundo por intermédio da paisagem.

\section{[A] paisagem parece traduzir para nós uma relação estreita e privilegiada com o mundo, representa como que uma harmo-nia preestabelecida, inquestionável, im-possível de criticar sem se cometer sa-crilégio. Onde estariam, pois, sem ela, nossos aprendizados das proporções do mundo e o de nossos próprios limites, pe-quenez e grandeza, a compreensão das coisas e a de nossos sentimentos? (CAU- QUELIN, 2007, p. 28)}

O ser humano tenta reconstruir a paisagem, e isso constitui arquitetura. O trabalho de Kishio Suga busca desvelar a arquitetura, para constituir uma paisagem e, em última instância, reconstruir a própria condição humana e o seu envolvimento com os elementos que derivam tanto da

Anais Alves Pereira, Paisagens suspensas nas obras de Kishio Suga. 
paisagem natural quanto dos espaços construídos.

Em Law of Peripheral Units ( Shüritsu) (Fig. 4) há uma evidente inspiração do artista nos jardins de pedras do Zen japonês ${ }^{4}$, que têm como finalidade propiciar ao ser humano um encontro com um estado elevado de consciência por meio da relação com o ambiente que o circunda. Na versão de Kishio Suga, as pedras são ligadas a uma estrutura de tubos de metal, com a utilização de cordas tensionadas em inúmeras diagonais que refletem os atravessamentos e as afetações mútuas entre as coisas, bem como sua condição de densidade.

Em todos os ângulos de observação, é possível ver três camadas de elementos cruzados: as cordas que sustentam as pedras, com sobreposições muito evidentes e constituindo uma trama densa; os tubos de metal, que também se cruzam uns sobre os outros e sobre as cordas; e as pedras em si, que, dispostas em variados graus de distância e aproximação umas das outras, dificultam vislumbrar um ângulo em que todas sejam vistas simultaneamente, sem que sobrepostas uma pela outra.
$O$ encadeamento de tramas, que se formam a partir da repetição e conexão entre esses três elementos, demonstra a teia de associações às quais todas as coisas estão submetidas. Com um olhar mais atento, é possível observar as linhas que se formam também na relação entre a obra e o espaço. Os traçados do piso, teto, paredes e lâmpadas formam camadas novas de cruzamento, que demonstram que todas as coisas do lugar estão vinculadas.

Nessa cadeia de afetações, o público se localiza na borda, como um observador que ativa esse campo. A maneira como Suga decidiu localizar a instalação no espaço expositivo - nas montagens que realizou, em 1997, no Hiroshima City Museum of Contemporary Art; em 1998, no Chiba City Museum of Art; e, em 2014, no Vangi Sculpture Garden Museum - coloca o próprio espectador em uma condição periférica em relação à obra, possibilitando apenas circundá-la, como é comum nos jardins Zen.

O conceito de "periferia" na obra de Suga reflete sobre a condição do material em relação ao ambiente ao redor, ao público e à 


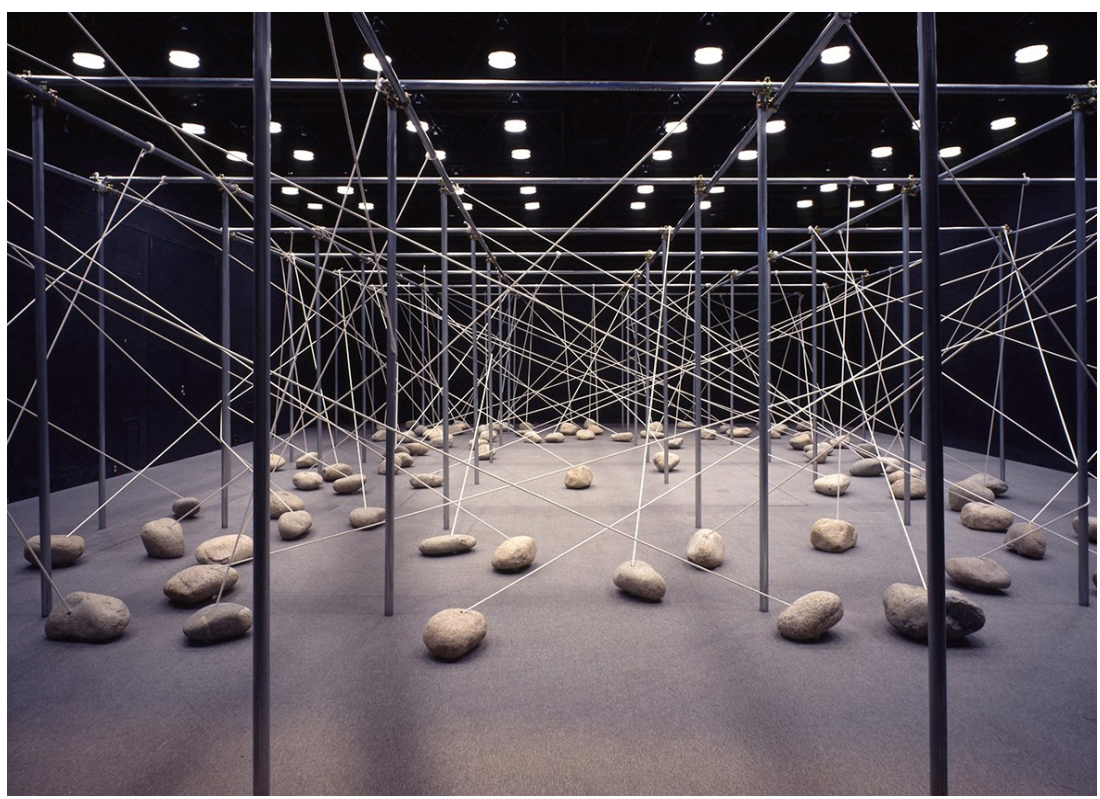

Fig. 4 - Kishio Suga, Law of Peripheral Units, 1997/1998.

instalação (tubos de aço, pedra, corda), dimensões variáveis

(Fonte: https://www.kishiosuga.com/installations-law-of-peripheral-units-1997. Acessado em 28/3/2019) 
formação de campos independentes em torno dos elementos. O próprio gesto de repetição no trabalho, e a organização deste dentro de uma estrutura geométrica, afirmam uma experiência espacial sem área central. Law of Peripheral Units propõe a percepção das rochas como unidades descentralizadas e isoladas em que cada uma é unidade periférica deslocada fisicamente de uma área de centralização e, simultaneamente, um centro energético em si mesmo, que define tudo ao redor como periferias de seu foco de magnitude.

A ausência da presença humana na unidade conformada pelas instalações do artista entra em contradição com a percepção daquele que as observa, uma suspensão temporal, interior ao ser humano em si. Paradoxalmente, é a ele que a pausa parece se destinar, é interno a ele que parece acontecer, ainda que esteja colocado de fora da situação. É ao observador que cabe reconhecer outras associações possíveis entre si. Em contrapartida, as relações estabelecidas entre os elementos no interior das instalações, bem como as escalas e proporções distorcidas entre espaço e objeto - que parecem não contemplar a dimensão do homem -, con- ferem autonomia e supremacia àquilo que ali é concebido, em detrimento do ser humano. No caso de Kishio Suga, isto se dá na existência das coisas em sua essência.

Talvez a virtude das obras até aqui apresentadas esteja em conferir matéria e espessura a dimensões metafísicas da vida. Permite a um só tempo um contato real com as coisas, uma relação direta e diversa com o mundo contemporâneo e reflete sobre a condição do espaço que habitamos, a natureza da qual nos ausentamos. Em um embate entre paisagem natural e paisagem construída, sua obra se afirma entre as materialidades que representam essa condição do natural versus o industrial.

Neste sentido, os trabalhos nos apresentam outros modos de se relacionar e de intervir no mundo, sem que estas ações sejam de aprisionamento e de domínio. Como se, para atingir o equilíbrio entre o imaterial e o material, fosse preciso abdicar das definições humanas para perceber outras paisagens que podem se desenrolar a partir da interação entre meio e matéria. 


\section{Notas}

${ }^{1}$ Os principais artistas do grupo Mono-ha foram Nobuo Sekine, Lee Ufan, Katsuro Yoshida, Susumu Koshimizu, Koji Enokura, Kishio Suga, Noboru Takayama e Katsuhiko Narita.

2 Trechos extraídos da entrevista com Kishio Suga, disponível em https://www.youtube.com/ watch? $v=9 s 4 \mathrm{Im} 8 \mathrm{pdWeU}$. Acessado em dezembro de 2019.

${ }^{3}$ A fala de Simon Groom foi citada no catálogo da exposição individual de Kishio Suga, Situations, que ocorreu na Pirelli HangarBicocca, em Milão, no ano de 2017.

${ }^{4}$ Os jardins de pedras dos templos Zen japoneses têm como filosofia principal criar um espaço que imite a essência da natureza, e não sua aparência, para servir de auxílio à meditação e ao encontro com verdadeiro significado da existência.

\section{Referências}

CAUQUELIN, Anne. A invenção da paisagem. São Paulo: Martins Fontes, 2007.

KWON, Miwon. Um lugar após o outro: anotações sobre site-specificity. Revista Arte \& Ensaios, EBA/UFRJ, Rio de Janeiro, n. 17, 2009.

LATOUR, Bruno. Jamais fomos modernos. São Paulo: Editora 34, 2013.
LATOUR, Bruno. Politics of Nature: East and West Perspectives. Ethics \& Global Politics, v. 4, n. 1, 2011.

SANTOS, Milton. Metamorfose do espaço habitado. São Paulo: Hucitec, 1988.

SANTOS, Milton. A natureza do espaço. São Paulo: Editora da Universidade de São Paulo, 2006.

SUGA, Kishio. The Start of Disappearance: As Things Deny Things. In Selected Writings of Kishio Suga: Spheres Will Not Be Closed. Yokohama: Yokohama Museum of Art, 1999.

SUGA, Kishio. Existence Beyond Condition. Bijutsu techo-, n. 324, fev. 1970.

SUGA, Kishio. Brochure Kishio Suga. Nova York: Dia Chelsea Gallery, 2017. 